(Aus dem Institut „Robert Koch" zu Berlin.)

\title{
Die Bedeutung des zur Nachkultur verwandten Nährbodens für die Beurteilung des Desinfektionserfolges.
}

\author{
Von \\ Dr. Bruno Lange, \\ Assistent am Institut.
}

Die Forderung, daß den Bakterien, an welchen Desinfektionsmittel geprüft werden sollen, in der Nachkultur durch Auswahl geeigneter Nährböden optimale Bedingungen der Entwick$1 \mathrm{u}$ g gegeben werden müssen, ist vor längerer Zeit bereits von $\mathrm{Gr} \mathbf{u}$ be $\mathbf{r}^{\mathbf{1}}$ ) erhoben worden.

- Von besonderer Bedeutung ist der Nährboden natürlich für solche Bakterien, die wie Pneumokokken, Diphtheriebacillen, höhere Ansprüche an die Qualität des Nährsubstrats stellen. Aber auch bei den Staph ylokokken, die als anspruchslos gelten, ist die Auswahl des Nährbodens für die Nachkultur keineswegs belanglos.

Süpfle und Dengler ${ }^{2}$ fanden als optimalen Nährboden für Staphylokokken eine 3 proz. Traubenzuckerbouillon, für Milzbrandsporen 3 proz. Traubenzuckerbouillon +5 proz. Serum. In einem der mitgeteilten Versuche sind z. B. nach 90 Minuten langer Einwirkung von $1 \%$ Phenol die Staphylokokken, in gewöhnliche Bouillon verbracht, nicht mehr angegangen, während bei über einer Stunde längerer Einwirkungszeit die Nachkultur in Traubenzuckerbouillon noch positives Ergebnis hatte.

In Anbetracht der Bedeutung solcher Feststellungen für die Methodik der Desinfektionsversuche schien eine Nachprüfung der Sü pfleschen Ergebnisse von Interesse zu sein.

Die nachfolgenden Untersuchungen habe ich gemeinsam mit der technischen Assistentin des Instituts, Fräulein $\mathrm{Karlbaum}$, angestellt.

1) Internat. Hyg.-Kongreß London 1891; C. f. Bact. 11, 115.1892.

$\left.{ }^{2}\right)$ Arch. f. Hyg. 85, 189. Vgl. auch S üpfle, Arch. f. Hyg. 87, 232. Eine Ergänzung der $\mathrm{S} u ̈ \mathrm{p} f \mathrm{leschen}$ Versuche ist kürzlich von Flesch erschienen (Hyg. Rundschau, Nr. 4, 1921). 
Es sind ausschließlich Suspensionsversuche. Wir benutzten als Testobjekt Staphylokokken (Kultur Staphyl. virul.), als Desinfektionsmittel Trikresol. Sowohl die Staphylokokken-Aufschwemmung - pro Schräg-Agar-Kultur $10 \mathrm{ccm} \mathrm{-} \mathrm{wie} \mathrm{die} \mathrm{Verdünnung} \mathrm{des}$ Desinfiziens wurde mit abgekochtem Leitungswasser hergestellt. Von der durch kurzes Zentrifugieren von gröberen Partikeln befreiten Bakterienemulsion wurde ein.Tropfen in $5 \mathrm{bzw} .1 \mathrm{ccm}$ der Desinfektionsflüssigkeit eingesät. Die zur Nachkultur dienenden flüssigen Nährböden (Röhrchen à $5-10 \mathrm{ccm}$ ) wurden mit je einem Tropfen bzw. 1 Oese der Staphylokokken-Desinfektionsmittelmischung beimpft. Konzentration des Mittels und Entnahmezeiten wurden abgestuft.

Zur Nachkultur gebrauchten wir neben Pferdefleisch- und aus menschlicher Placenta hergestellter Bouillon die gleiche Bouillon mit Zusatz von 3\% Traubenzucker und 10\% Pferdeserum. In einem Versuch wurde auch Bouillon.mit Leberstückchen mit und ohne gleichzeitigen Traubenzuckerzusatz verwandt.

Die im Desinfektionsversuch geprüften verschiedenen Nährböden wurden gleichzeitig nach zwei Methoden a uf ihre die Keimentwicklung fördernden Eigenschaften hin untersucht; und zwar erstens durch Beimpfung des Nährbodens mit abgestuften kleinsten Bakterienmengen (herunter bis $1 / 100000$ Millionen Tropfen der zum Versuch b $\epsilon$ nutzten Bakterienemulsion).

Nach der zweiten Methode wurden die einzelnen Nährböden mit 1/10000 Tropfen der Staphylokokkenemulsion beimpft, dann sofort, nach 2 und 4 Stunden ein Tropfen der beimpften Nährflüssigkeit mit Agar gemischt zur Platte ausgegossen.

Während die erste Art der Prüfung uns lediglich die Tatsache anzeigt, bis zu welcher stärksten Verdünnung der Einsaatmenge noch Wachstum der Bakterien auftritt, erhalten wir nach der zweiten Aufschluß über die Schnelligkeit der Keimvermehrung in den einzelnen zu prüfenden Nährböden. Möglicherweise lieferten diese Verfahren eine Erklärung der Geeignetheit bestimmter Nährböden zur Nachkultur, wenn sich nämlich zeigen würde, daß die nach der beschriebenen Methode nachweislich besten auch zur Nachkultur am geeignetsten sind.

Ferner wurde auf etwaige Entwicklungshemmung durch Spuren des Desinfektionsmittels in der Nachkultur in der Weise untersucht, daß die einzelnen Nährlösungen mit dem Doppelten der in Frage kommenden Menge des Desinfektionsmittels beschickt und danach mit $1 / 100$ Millionstel Tropfen der Staphylokokkenemulsion beimpft wurden.

Die Beobachtungszeit in sämtlichen Versuchen betrug 5 Tage. Im folgenden sei ein derartiger Versuch wiedergegeben. 
verwandten Nährbodens für die Beurteilung des Desinfektionserfolges. 127

Tabelle I. 6. XI. 1920 .

Wirkung von Trikresol auf Staphylokokken iu Leitungswasser.

Einsaat: 1 Tropfen pro $5 \mathrm{ccm}$ Desinfiziens. Aussat: 1 Tropfen auf $6 \mathrm{ccm}$ Nachkultur.

Desinfektionsversuch

Kontrollen

\begin{tabular}{|c|c|c|c|c|c|c|c|c|c|}
\hline \multirow{2}{*}{ Zur Nachkultur } & \multicolumn{6}{|c|}{ Konzentration in \% } & \multirow{2}{*}{$\begin{array}{l}\text { Wachstum noch bei } \\
\text { welcher kleinsten } \\
\text { Linsaatmenge? }\end{array}$} & \multirow{2}{*}{ 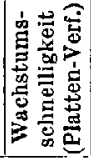 } & \multirow{2}{*}{$\begin{array}{l}\text { Entwicklungshemmung } \\
\text { (E. H.) durch das Des- } \\
\text { inflziens in der Nach- } \\
\text { kultur. Einsaat } 2 \text { Trpf. } \\
\text { d. Bakterien-Des.-Gem. }\end{array}$} \\
\hline & 0,6 & 0,4 & 0,3 & 0,2 & $0,1 \tilde{5}$ & 0,1 & & & \\
\hline Placentabouillon $\left\{\begin{array}{l}\text { t } \\
\text { I }\end{array}\right.$ & $\begin{array}{l}0 \\
0\end{array}$ & $\begin{array}{l}0 \\
0\end{array}$ & $\begin{array}{l}+ \\
0\end{array}$ & $\begin{array}{l}+ \\
+\end{array}$ & $\begin{array}{l}+ \\
+\end{array}$ & $\begin{array}{l}+ \\
+\end{array}$ & $1 / 10$ M. $+1 / 100$ M. - & + & $\begin{array}{l}\text { E. H. }=+ \text { entspr. den } \\
\text { Konzentr. } 0,6 \text { u. } 0,4 \\
\text { E. } H .=0 \text { b. } 0,3-0,1\end{array}$ \\
\hline $\begin{array}{l}\text { Placentabouillon } \\
+3 \% \text { Traubenzucker }\end{array}$ & $\begin{array}{l}0 \\
0\end{array}$ & $\begin{array}{l}0 \\
0\end{array}$ & $\begin{array}{c}++ \\
+\end{array}$ & $\begin{array}{l}++ \\
++\end{array}$ & $\begin{array}{l}++ \\
++\end{array}$ & $\begin{array}{l}++ \\
++\end{array}$ & $1 / 100$ M. $+1 / 1000$ M. - & ++ & E. $\mathrm{H} .=0$ \\
\hline Pferdefleischbouillon $\left\{\begin{array}{l}a \\
b\end{array}\right.$ & $\begin{array}{l}0 \\
0\end{array}$ & $\begin{array}{l}0 \\
0\end{array}$ & $\begin{array}{c}++ \\
(+)\end{array}$ & $\begin{array}{l}++ \\
++\end{array}$ & $\begin{array}{l}++ \\
++\end{array}$ & $\begin{array}{c}++ \\
++\end{array} \mid$ & $1 / 100$ M. $+1 / 1000$ M. - & + & E. H. $=0$ \\
\hline 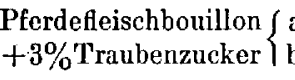 & $\begin{array}{l}0 \\
0\end{array}$ & $\begin{array}{l}0 \\
0\end{array}$ & +++ & $\begin{array}{l}++ \\
++\end{array}$ & $\begin{array}{l}++ \\
++\end{array}$ & $\begin{array}{l}++ \\
++\end{array}$ & $1 / 100000 \mathrm{M} .+$ & + & E. $\mathrm{H} .=0$ \\
\hline Serumbouillon \{ & $\left|\begin{array}{c}(+) \\
0\end{array}\right|$ & $\begin{array}{c}(+) \\
0\end{array}$ & $\begin{array}{l}++ \\
++\end{array}$ & $\begin{array}{l}++ \\
++\end{array}$ & $\begin{array}{l}++ \\
++\end{array}$ & $\left|\begin{array}{l}++ \\
++\end{array}\right|$ & $\mid 1 / 1000$ M. $+1 / 10000$ M. - & + & E. $\mathrm{H} .=0$ \\
\hline $\begin{array}{l}a=\text { Aus } \\
b=\text { Aus }\end{array}$ & $\begin{array}{l}\text { at no } \\
\text { at na }\end{array}$ & $\begin{array}{r}\text { ach } \\
\text { ach } 2 \\
++= \\
+=\end{array}$ & $\begin{array}{l}4 \text { Stu } \\
\text { Stur } \\
=\text { star }\end{array}$ & $\begin{array}{l}\text { unde, } \\
\text { nden. } \\
\text { rkes }\end{array}$ & in & 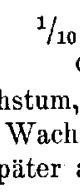 & $\begin{array}{l}\text { M. usw. }=1 / 10 \text { Millio } \\
\text { der Staphyl.-Emulsior }\end{array}$ & $\begin{array}{l}\text { onstel ' } \\
\text { n. }\end{array}$ & Tropfen \\
\hline
\end{tabular}

Aus dem Versuch ist ersichtlich, daß es in der Tat auch für Staphylokokken nicht gleichgültig ist, welcher Nährboden zur Nachkultur verwandt wird. Auffällig sind die unterschiedlichen Ergebnisse besonders bei Verwendung von Serumbouillon neben Placentabouillon. Während die Staphylokokken z. B. nach $1 / 4$ stündiger Einwirkung von $0,4 \%$ Trikresol in der Placentabouillon kein Wachstum zeigen, findet in Serumbouillon nach gleichlanger Einwirkung von $0,6 \%$ Trikresol, wenn auch verzögert, noch Keimentwicklung statt.

Ordnen wir die Nährböden nach ihrer Fähigkeit, die Keimentwicklung nach abgeschlossener Desinfektion zu begünstigen, so steht an erster Stelle die Serumbouillon, es folgt Placentabouillon und Traubenzucker, gewöhnliche Pferdefleischbouillon, Pferdefleischbouillon und Zucker, mit letzterer gleichwertig die Placentabouillon.

Nach der Prüfung der Bakterienentwicklung in den einzelnen Nährböden bei kleinster Einsaat verhält sich am besten die Pferdefleischbouillon mit Zuckerzusatz und die Serumbouillon, am wenigsten gut die Placentabouillon ohne Zuckerzusatz. 
Die Wachstumsenergie der Staphylokokken, durch Plattenkultur geprüft, ist in der Blutbouillon mit Zucker etwas stärker als in den übrigen.

Eine Entwicklungshemmung durch eingebrachte Mengen des Desinfektionsmittels fand lediglich in der Blutbouillon statt, in den übrigen Nährböden nicht.

Die Ergebnisse der Kontrolluntersuchung lassen sich, wie die Tabelle zeigt, zu denjenigen des Desinfektionsversuchs nicht ohne weiteres in Beziehung setzen. Offenbar waren in unserem Versuch für den Ausfall der Nachkultur zwei Faktoren von Bedeutung. Neben der wachstumsfördernden Fähigkeit des Nährbodens scheint sein Vermögen, Spuren des Desinfektionsmittels unschädlich zu machen, eine Rolle zu spielen. Letzteres mag im besonderen für die Serumbouillon zutreffen. Daß Kresole durch eiweißhaltige Medien speziell auch durch Serum in ihrer Wirkung zum Teil neutralisiert werden, konnten u. a. Schiemann und Landau ${ }^{1}$ ) bei ihren Händedesinfektionsversuchen̉ mit Betalysol und Sagrotan nachweisen. Weitere Versuche in unserm Laboratorium, die demnächst mitgeteilt werden, haben das bestätigt.

Die Unterschiede zwischen den Nährböden hinsichtlich ihrer Geeignetheit für die Nachkultur treten besser in Erscheinung, wenns die Entnahmezeiten mehr abgestuft werden, wie dies in der Süpfle. schen Arbeit geschieht.

Ein Versuch dieser Reihe sei darum gleichfalls wiedergegeben.

Tabelle II. 16. XI. 1920.

Wirkung von $0,4 \%$ Trikresol auf Staphylokokken in Leitungswasser.

Einsaat: 1 Tropfen Staph-Emulsion pro $1 \mathrm{ccm}$ Desinfiziens.

Aussat: 1 Oese auf 4 cm Nachkultur.

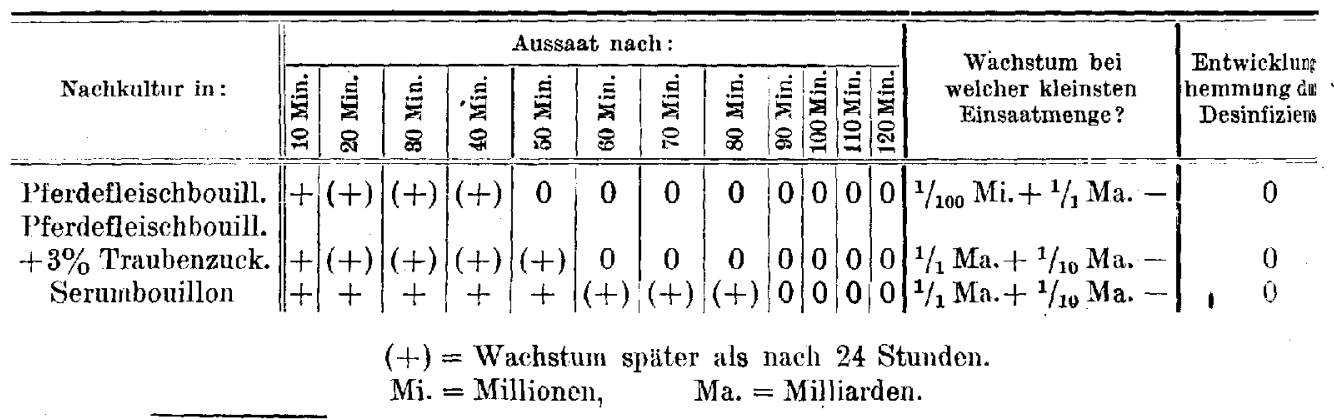

1) Zeitschr. f. Hyg. 88, $129 \mathrm{ff}$. 
Wir sehen auch in diesem Versuch wieder das beste Wachstum in der Nachkultur bei der Serumbouillon, wesentlich schlechter ist die Entwicklung in gewöhnlicher Bouillon. Ein günstiger Einfluß des Traubenzuckerzusatzes ist, wie teilweise auch im ersten Versuch, vorhanden, aber geringer als nach.der Arbeit Süpfles zu erwarten wäre.

Bei der Keimentwicklungsprüfung mittels kleinster Einsaat zeigte sich die Serumbouillon und die Zuckerbouillon etwas besser als gewöhnliche Pferdefleischbouillon. Entwicklungshemmung durch Spuren des Desinfektionsmittels in der Nachkultur war in keinem Fall nachweisbar.

Zusammenfassend kann gesagt werden: Es ergeben sich aus unseren Versuchen in der Tat im Sinne S ü pfles gewisse - allerdings nicht sehr beträchtliche Unterschiede im Verhalten der Nachkultur nach dem jeweils hierzu benutzten Nährboden.

Diese Unterschiede sind offenbar hauptsächlich zurückzuführen auf die durch Zusatz von Nährstoffen zu der Bouillon verbesserten Wachstumsbedingungen der Bakterien. Da in unseren Versuchen auch die Bouillon ohne Zusätze sich als hinreichend günstiger Nährboden erwies, wie die Kontrollprüfungen ergaben, so konnte auch durch solche Zusätze nur eine verhältnismäßig geringe Steigerung der Bakterienentwicklung erzielt werden; besonders gab die Traubenzuckerbouillon nicht immer bessere Resultate. Wo sich überhaupt eine Verbesserung zeigte, war der Ausschlag geringer als in den Versuchen von Süpfle.

Der Effekt von Zusätzen wie Zucker, Organstückchen und Serum zu an sich schlechten Nährböden muß naturgemäß viel bedeutender sein.

Wie aus den Tabellen ersichtlich ist, gehen die Ergebnisse mit den Kontrollprüfungen, in denen die gleichen Nährböden daraufhin verglichen wurden, inwieweit sie ungeschädigten Keimen der gleichen Art bei kleiner Einsaat günstige Wachstumsbedingungen boten, nur in gewissem Grade parallel.

In der Einleitung ist kurz darauf hingewiesen worden, daß die Beschaffenheit der zur Nachkultur verwandten Nährböden eine größere Rolle spielen muß bei Bakterien, die wie Pneumokokken und Diphtheriebacillen an den Nährboden höhere Ansprüche stellen.

Daneben dürfte die besondere Fähigkeit des Nährbodens, Spuren des Desinfektionsmittels zu neutralisieren, den Erfolg der Nachkultur in Desinfektionsversuchen mit bedingen.

Daß in Versuchen mit Milzbrandsporen die Verwendung optimaler Nährböden geradezu ausschlaggebend ist, lehrt folgender mit Sagrotan und Milzbrandsporen angestellter Abtötungsversuch. 


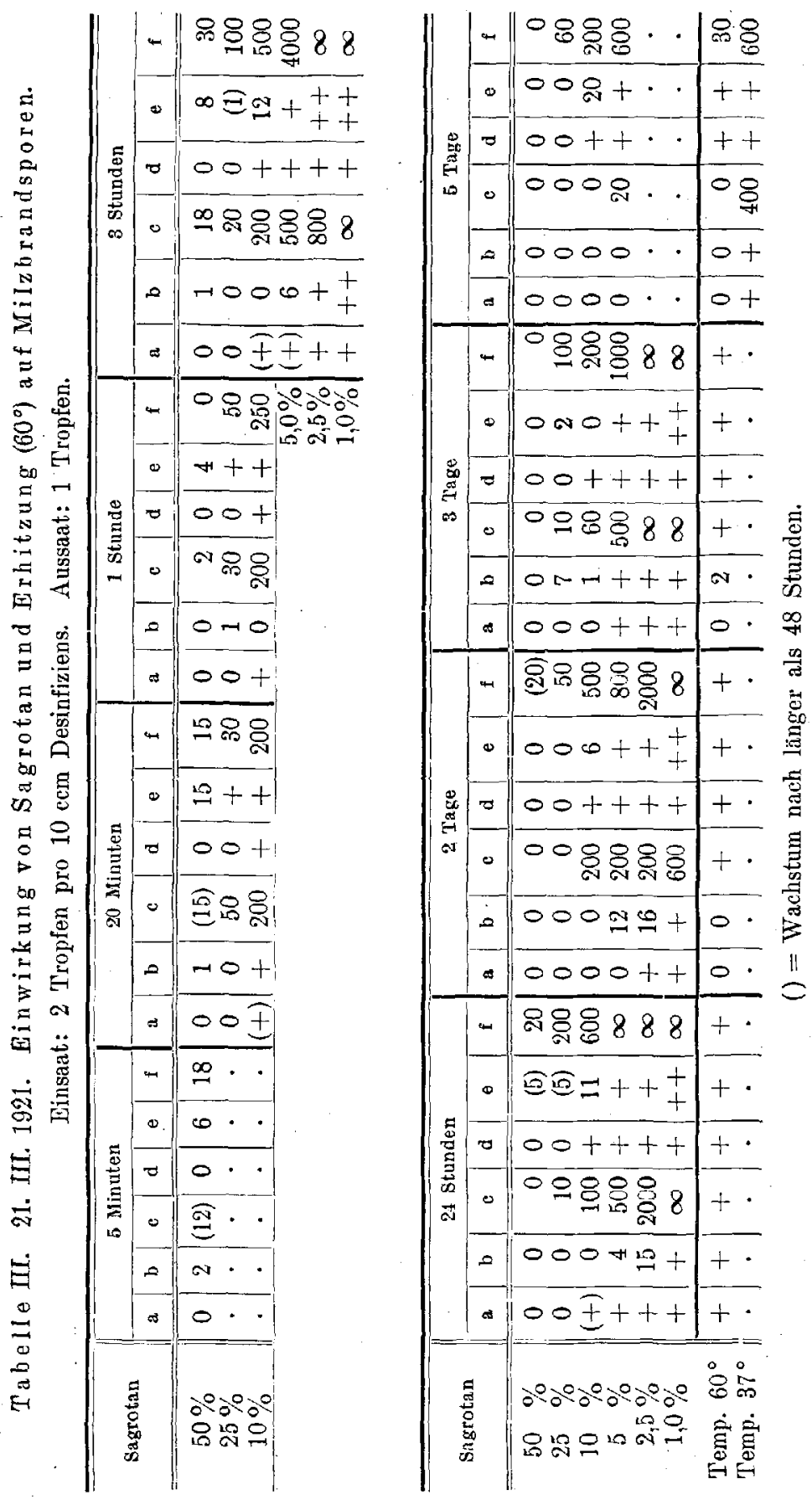


verwandten Nährhodens für die Beurteilung des Desinfektionserfolges.
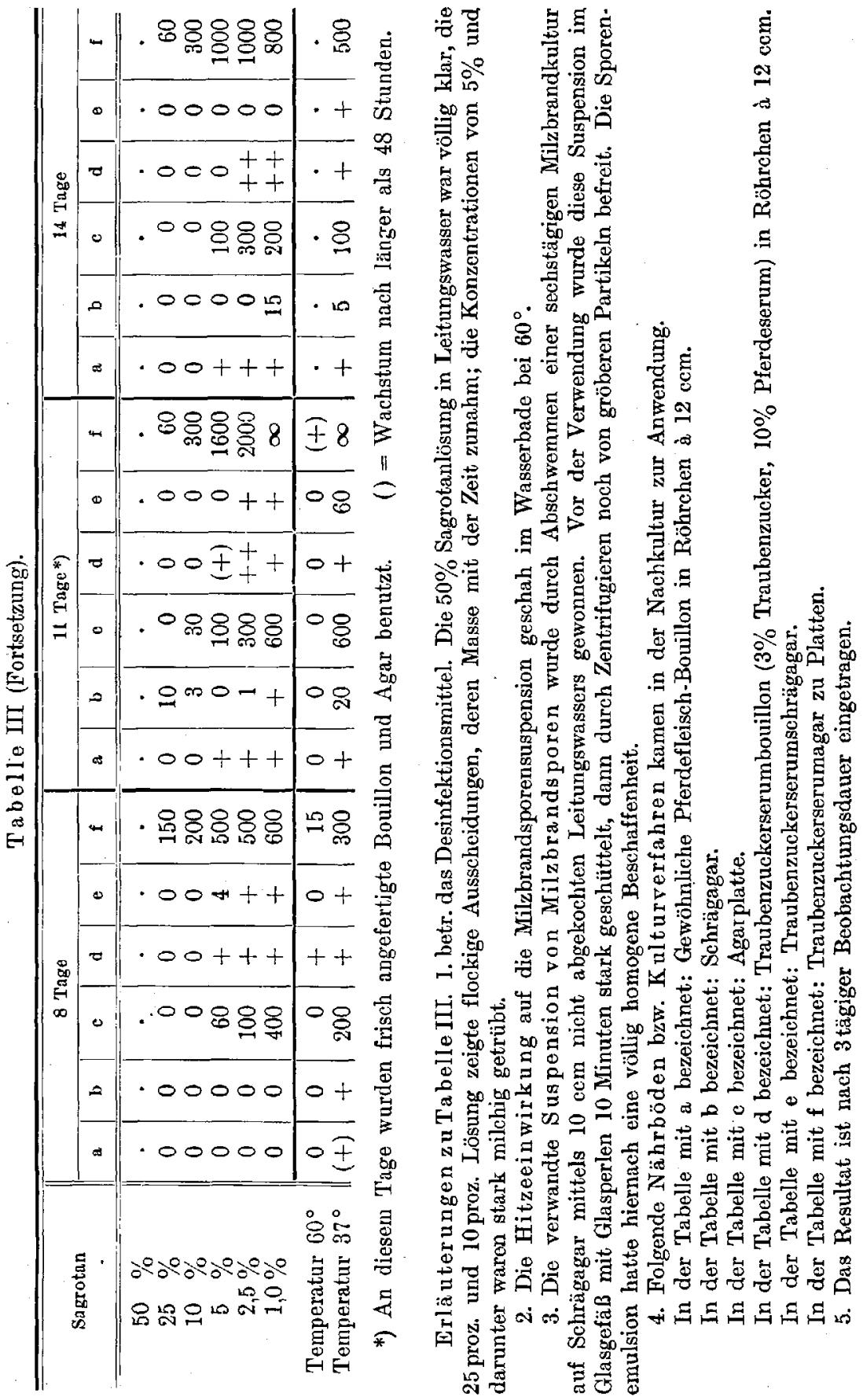
In diesem Versuch sollte in erster Linie festgestellt werden, ob die bereits von Neufeld und Karlbaum${ }^{1}$ ) in ihrer Arbeit kurz erwähnte wesentliche Verbesserung des Wachstums in der Nachkultur durch Anwendung des Plattenverfahrens im Milzbrandsporen-Abtötungsversuch allein auf Unschädlichmachung des in die Kultur mit übertragenen im besondern seitens der Bakterien adsorbierten Desinfektionsmittels beruht.

Zu diesem Zweck wurde mit dem Sagrotanversuch ein Hitzeabtötungsversuch bei $60^{\circ}$ verbunden und zur Nachkultur die gleichen Nährböden und Kulturverfahren benutzt. Handelte es sich lediglich um Neutralisationswirkungen gegenüber Spuren des Desinfiziens in der Nachkultur, so durften nennenswerte Unterschiede in der Entwicklungsfähigkeit der hitzegeschädigten Sporen bei Verwendung der gen. Kulturverfahren nicht hervortreten, da hier eine Mitübertragung des Desinfektionsmittels in die Nachkultur nicht in Frage kommt.

Die Ergebnisse des über 14 Tage sich erstreckenden Sagrotanversuchs sind folgende:

1. Gewöhnliche Bouillon in Röhrchen ist unter den vorliegenden Versuchsbedingungen zur Nachkultur ungeeignet. Wie die Tabelle zeigt, findet z. B. in Bouillon bereits nach 20 Minuten langer Einwirkung von 25\% Sagrotan ein Auskeimen der Sporen nicht mehr statt. Die Abtötung der Sporen ist in Wirklichkeit (Serumagarplatten!) durch eine 25 proz. Lösung noch nach 14 Tagen nicht erfolgt. Ähnliche starke Abweichungen sind in dem Erfolg der Nachkultur für die übrigen Konzentrationen aus der Tabelle zu entnehmen. (Daß nach 11 und 14 tägiger Einwirkung des Sagrotans in $1-5$ proz. Lösung auf Bouillon noch regelmäßig, auf Schrägagar einige Male Auswachsen der Sporen erfolgt, während nach 5 und 8 Tagen die Nachkultur auf Bouillon und Schrägagar steril geblieben ist, mag damit zusammenhängen, daß nach 11 und 14 Tagen frisch a bg efüllte Nährböden verwandt wurden.)

2. Aussaat auf gewöhnlichen Schrägagar gibt etwas bessere Bedingungen für die Sporenauskeimung, erheblich bessere aber bereits das Plattenverfahren mit demselben Agar.

3. Der Zusatz von Traubenzucker und Serum zu Bouillon und Schrägagar hat bereits einen deutlichen EinfluB auf das Sporenwachstum; die weitaus besten Bedingungen für die Sporenentwicklung wurden aber durch Verwendung von Traubenzuckerserumagarplatten geschaffen.

Die beschriebenen Unterschiede treten im Hitzeabtötungsversuch lange nicht so stark hervor wie im Sagrotanversuch. Die Agarplatten ergeben aber auch hier besseres Wachstum als Schrägagar und

1) Zeitschr. f. Hyg. 91, 32. 1920. 
der Einfluß des Zusatzes von Zucker und Serum ist bei allen drei Nährböden recht erheblich. Hier können die Unterschiede in dem Ergebnis der Nachkultur lediglich durch die verschiedene Fähigkeit der Nährböden bzw. Kulturverfahren das Auskeimen der Sporen zu begünstigen hervorgerufen sein. Es muß daher dieser Eigenschaft der Nährböden auch im Sagrotanversuch eine Bedeutung zuerkannt werden, eine größere kommt angesichts der starken Differenzen in der Nachkultur hier aber wohl dem Vermögen der Nährböden zu, wachstumshemmende kleinste Mengen des Desinfiziens unschädlich zu machen. In diesem Sinne wirkt offenbar die Einbettung der mit Sagrotan behandelten Sporen in ein kollcidales Medium wie Agar; vielleicht spielt der Agar hier dieselbe Rolle, wie die Tierkohle in den jüngst von Sü pfle und Müller ${ }^{1}$ ) mitgeteilten Desinfektionsversuchen mit Sublimat. Dieser Faktor fällt bei dem Hitzeversuch weg, daher besteht hier ein geringerer Unterschied zugunsten der Agarplatte. Leicht begreiflich ist, daß die Qualität des Nährbodens verbessernde Zusätze das Auskeimen begünstigen. Wie weit bei der Desinfektionsmittelprüfung gegenüber Milzbrandsporen in unserer Versuchsanordnung der eine Faktor, wie weit der andere für den Ausfall der Nachkulturprüfung verantwortlich zu machen ist, das ist schwer zu entscheiden, besonders wenn man berücksichtigt, daß jede Verbesserung der allgemeinen Wachstumsbedingungen zugleich die Widerstandsfähigkeit der Sporen dem noch anhaftenden Desinfiziens in der Nachkultur gegenüber steigern muß. Daher ist hier das Wort "optimaler Nährboden" in dem weiteren Sinne gebraucht worden, daß damit nicht nur die wachstumsfördernden Eigenschaften, sondern auch etwaige spezifische Neutralisationswirkungen dem Desinfiziens gegenüber bezeichnet werden. Auch in der Praxis wird man die beiden an sich ja grundverschiedenen Faktoren nicht immer auseinanderhalten können; wenn z. B. mit Sublimat behandelte Keime in einem Kulturmedium nicht mehr auskeimen, dagegen ein Tier infizieren, so bleibt es offen, inwieweit dabei eine Neutralisation von Sublimatresten durch Eiweiß und inwieweit der Tierkörper als „optimaler Nährboden“ im eigentlichen Sinne des Wortes ausschlaggebend gewesen ist.

Wahrscheinlich wird bei Anwendung höherer Konzentrationen des Abtötungsmittels die Neutralisation des Desinfiziens, bei niederen Konzentrationen die allgemeine Förderung der Keimentwicklung eine größere Rolle spielen. Ferner wird der erstgenannte Faktor um so größeren Einfluß haben, je stärker das betreffende Desinfiziens von den Keimen adsorbiert wird und je mehr die nachträgliche Wirkung dieser adsorbierten Mengen des Mittels für den Ausfall des Versuchs entscheidend ist.

1) Arch. f. Hyg. 89, 351. 
134 B. Lange: Die Bedeutung des zur Nachkultur verwandten Nährbodens usw.

Unsere Versuche haben erneut veranschaulicht, in welchem Grade bei Desinfektionsmittelprüfungen an Milzbrandsporen, aber auch wenngleich geringer - an Staphylokokken, den beiden als Testobjekt gebräuchlichsten Bakterienarten, der Ausfall der. Versuche von der Wahl des Nährbodens zur Nachkultur abhängig ist.

Welcher Nährboden bzw. welches Kulturverfahren als optimal anzusehen ist, diese Frage kann nur von Fall zu Fall entschieden werden und richtet sich hauptsächlich nach dem Testmaterial und dem zu prüfenden Desinfektionsmittel, dessen Unschädlichmachung in der Nachkultur angestrebt wird.

Die Verwendung optimaler Nährböden zur Nachkultur wird im allgemeinen nicht nur für Untersuchungen angebracht sein, die die Auffindung absoluter Werte für bestimmte Desinfektionsmittel anstreben, was ja ohne weiteres einleuchtet, sondern auch für vergleichende Prüfungen, die sich mit der Ermittlung relativer Werte begnügen.

Inwieweit sie da zu fordern ist, wo es sich um die Bewertung eines Desinfiziens für einen bestimmten praktischen $Z$ weck handelt, wird von den Bedingungen der Weiterentwicklung abhängen, die das der Desinfektion unterworfene Bakterienmaterial in dem betreffenden Fall voraussichtlich in der Praxis findet. 